\title{
UN SUPLEMENTO DE EL LIBERAL EN LOS INICIOS DE LA LITERATURA INFANTIL ESPAÑOLA
}

\author{
RAMÓN F. LLORENS GARCÍA \\ ramon.llorens@ua.es \\ Universidad de Alicante
}

\begin{abstract}
Resumen
Durante la segunda mitad del XIX y los comienzos del Xx, las publicaciones para niños alcanzaron uno de los momentos de mayor auge. La relevancia de los autores que colaboraban en sus cabeceras y los proyectos editoriales que se pusieron en marcha indicaban las líneas por las que iba a desarrollarse la literatura infantil española que tendría su «Edad de Oro» durante las tres primeras décadas del siglo xx. En el fin de siglo, el suplemento de El Liberal del 3 de enero de 1897 destacó como antecedente de lo que serían las revistas para niños. Sus destinatarios, el lector adulto y el lector infantil. El adulto conocería las líneas de investigación sobre el niño desde el punto de vista psicológico y pedagógico; el infantil accedería a cuentos y poemas elegidos para él, que podrían ser leídos también por los adultos.
\end{abstract}

Palabras clave: literatura infantil, prensa para niños. educación literaria.

\begin{abstract}
During the second half of the $19^{\text {th }}$ century and the beginnings of the $20^{\text {th }}$, one of the highest peaks was reached in children's publi2cations. The relevance of the authors working in the different issues and the editorial projects that were started indicated the paths to be followed by Spanish Children's Literature, which would have its "Golden Age" in the first three decades of the $20^{\text {th }}$ century. At the end of the $19^{\text {th }}$ century, the supplement of El Liberal of the third of January 1897 stood out as an antecedent of what children's magazines would become. It was addressed both to the adult and the child reader. The adult would get to know the lines of investigation on children from the pedagogic and psychological point of view; the child would access to tales and poems selected for him, and which could be also read by the adults.
\end{abstract}

Keywords: childrens literature, press for children, literary education.

Anales, 26, 2014, pp. 257-274

DOI: 10.14198/ALEUA.2014.26.11 
«Los periódicos para niños fueron el verdadero germen de la literatura infantil». Ya Carmen Bravo-Villasante (1985: 85) puso de relieve la importancia que las colaboraciones literarias en la prensa para niños desempeñaron en los comienzos de la literatura infantil decimonónica. Autores y textos conformaron un importante corpus que contribuyó a asentar las bases sobre las que se desarrollarían la prensa y la literatura infantil durante el siglo XX.

Las revistas y los periódicos para niños lograron tener durante el siglo XIX una relevante presencia en la cultura de la época, aunque solo algunos subsistieron. Antecesores de la «prensa pedagógica» (Checa, 2002: 43) y herederos de la prensa infantil de la Ilustración -de la que la Gazeta de los niños ${ }^{1}$ es un ejemplo apropiado- las publicaciones para niños ofrecieron una amplia gama durante el siglo XIX: desde una primera etapa en la que «deleitaban poco, huyen de la imaginación, de la fantasía, porque se atacaba al Romanticismo. Luego se irán introduciendo los cuentos de fantasía e imaginación. Tenía un fin moralizante, ya que la religión era un pilar fuerte de la sociedad» (Arango, 1989: 14) hasta las de finales del siglo que «hacen de esta época la más rica en novedades» (Chivelet, 2009: 60). Conviene destacar que, tras los periódicos de las primeras décadas del régimen liberal, El Amigo de la Niñez (18401842), El Amigo de la Juventud (1841), El Museo de los Niños (1842-1843), El Mentor de la Infancia (1843-1845), el Álbum de los Niños (1845), el Álbum de la Infancia (1845) (Checa, 2002; Chivelet, 2009; García, 1992), la mayoría de los periódicos dirigidos a los niños ya «no tienen como destinatario principal al niño de familia de clase alta, sino al profesorado de enseñanza primaria» (Checa, 2002: 44).

En este contexto en el que se aprecian los comienzos de la literatura dedicada al niño, pueden señalarse tres circunstancias que contribuyeron a la multiplicación de las cabeceras infantiles durante la segunda mitad del siglo al margen de las nuevas técnicas de impresión. En primer lugar, la divulgación del pensamiento pedagógico de Johann Heinrich Pestolozzi y su discípulo Friedrich Froebel -cuya pedagogía de la intuición influiría en la Institución Libre de Enseñanza-. En segundo lugar, el papel pujante de la burguesía que «favorecía una renovada preocupación por el papel del niño, por su lugar en esa sociedad y por las condiciones de la más adecuada educación, conforme a los correspondientes modelos ideológicos» (García, 1991: 17). En tercer lugar, la literatura para niños como mercado. Eran periódicos caros, dirigidos

1. Primer periódico español dedicado a los niños publicado en 1798. Se define como «Principios generales de moral, ciencia y artes, acomodados a la inteligencia de la primera edad». Noticias, obritas teatrales, textos divulgativos... eran sus contenidos (Chivelet, 2009: 26). 
a una clase social alta que podía comprarlos directamente o suscribirse a ellos. Para Castro (1969: 206) «tenían como características: la pretensión pedagógica, la introducción lenta pero constante de la imagen, los precios altos, las tiradas escasas, distribución por suscripción y entre colegios, familias acomodadas y asociaciones pías, impresión cuidada».

La máxima horaciana del «instruir deleitando» que se reflejaba desde los primeros textos para niños se extenderá hasta la primera década del siglo xx y su componente didáctico-moralizante prevaleció en numerosas ocasiones sobre el texto literario hasta desvirtuarlo y convertirlo en un mero pretexto para la instrucción. Los periódicos infantiles del siglo XIX «eran didácticos, fundamentalmente. Respecto al formato y a la estructura eran como libros de texto, escritos a dos columnas. El fin que tenían era de instruir, educar y deleitar» (Arango, 1989: 14). Los temas científicos, divulgativos y de entretenimiento compartieron páginas con los cuentos, los poemas o las obrillas teatrales. Debe tenerse en cuenta que las publicaciones infantiles iban dirigidas a los niños y, también, a las familias.

Hojeando un periódico de hace cien o cincuenta años aparece evidente el tono serio de los escritos, está a las claras el intento moralizador, prevalece el texto respecto de las ilustraciones, la paginación se repite monótonamente. Esta seriedad dominante nacía no sólo de las concepciones pedagógicas del tiempo y de un conocimiento de la psicología insuficientemente profundo -sobre todo la del adolescente-, sino también de que aquellos periódicos se dirigían a las familias, además de a los jóvenes lectores, mientras que la monotonía era consecuencia seguramente de un cierto tono gris del gusto, pero sobre todo de la pobreza de medios tipográficos (Petrini, 1981: 161).

A pesar de su auge, la prensa infantil española estuvo sometida durante el siglo XIX y los comienzos del XX a una servidumbre pedagógica que lastró sus contenidos literarios. Tal servidumbre no fue distinta de la que la propia literatura infantil había sufrido.

Durante la transición del siglo XIX al actual, la literatura infantil española estaba en manos de un fuerte didactismo y una filantropía mal entendida. La candidez y la pedantería llenaban sus páginas y al niño se le hablaban de desgracias y más desgracias, de buenos comportamientos -tan buenos que resultan irreales-, con la intención clara de inculcarle el valor supremo de la virtud y el sacrificio (García, 2004, 31).

Las publicaciones literarias para niños de finales del siglo XIX y de comienzos del XX aparecieron en la prensa específica para ellos (El Camarada, Los Niños, El Álbum de los Niños, Infancia) o en forma de secciones y suplementos en la prensa para adultos (Blanco y Negro, El Liberal) hasta consolidarse finalmente, ya en las décadas veinte y treinta del siglo $\mathrm{Xx}$, como revistas independientes 
(Chiquilin, Pinocho, Macaco) en las que colaboraron algunos de los autores más importantes de la época -a los que me referiré más abajo- o siguieron como secciones en las publicaciones para adultos (Gente Menuda en Blanco y Negro, Los lunes de El Imparcial, Estampa, Crónica).

En la prensa infantil decimonónica dos periodistas y escritores, colaboradores habituales de la prensa general, destacaron por su obra de creación para niños y por ser impulsores de numerosas publicaciones para la infancia, Carlos Frontaura Castillo y Manuel Ossorio y Bernard (Chivelet, 2009; García, 1992). Carlos Frontaura contribuyó a la visibilidad de la prensa infantil con las cabeceras Los Niños, que comenzó a publicarse en 1870 -tendría varias etapas en Madrid y en Barcelona-, La Primera Edad y La Edad Dichosa. Manuel Ossorio «el autor preferido de la infancia» con La Niñez, El Mundo de los Niños y La Edad Dichosa.

La renovación de las publicaciones para niños y con ella la renovación de la literatura infantil española no llegó hasta finales del siglo XIX en que «existían ya antecedentes claros de las que después serían corrientes y tendencias propias del siglo Xx, y que harían posible el desarrollo posterior de una evolución creadora [...] que abarcaría las tres primeras décadas del siglo XX» (García, 1992: 17). En estas tres primeras décadas, la «Edad de Oro» de la literatura infantil española (Llorens, 2011) conoció su época de mayor esplendor: publicación de revistas con propuestas estéticas de vanguardia, secciones infantiles en la prensa general, colecciones y editoriales en las que colaboran escritores de la época que no habían publicado para niños; a su vez, autores de literatura infantil -algunos de los cuales cultivan también la literatura para adultos, la crítica de arte o de teatro: Manuel Abril o Antonio Robles- pasaron a formar parte de las redacciones de las revistas, de los suplementos infantiles, de las tertulias y de los cenáculos literarios: Ramón Gómez de la Serna había reunido en Pombo a Salvador Bartolozzi, Manuel Abril, Tomás Borrás; en la revista Pinocho colaboraban Manuel Abril, Magda Donato, Edgar Neville, Antonio Robles; y lo mismo observamos en «Los Lunes» de El Imparcial, en Crónica o en Estampa. A partir de la proclamación de la Segunda República, se vivió una evidente preocupación por la formación del niño lector y por la promoción de la lectura, debido al interés del Estado por integrar el libro infantil en sus políticas culturales y educativas y por darle a la literatura infantil una mayor visibilidad social (Franco, 2005: 257). Durante la Segunda República, la actividad editorial creció con nuevas colecciones de CIAP, Cenit, Aguilar, Espasa-Calpe, Rivadeneyra.

Entre las características de las revistas infantiles aparecidas entre 1900 y 1936, destacan dos hechos: primero, la variedad de sus planteamientos en 
busca constante para ganar la fidelidad de ese público, y, en segundo lugar, la acogida que en ellas tuvieron las creaciones literarias de carácter más innovador. Si bien hasta los años veinte los moldes decimonónicos conservaban su vigencia en aquellas revistas, la década siguiente conoció importantes cambios en sus orientaciones. (García, 1992: 193)

La importancia de la posteriormente llamada educación informal en de los niños del XIX resultó decisiva a través de la prensa infantil. En ella cabían todos los aspectos relacionados con la enseñanza: ciencias naturales, matemáticas, literatura, y con el entretenimiento: pasatiempos, concursos... incluso su diseño, según Arango era más parecido a un libro de texto, como hemos citado más arriba. En estas circunstancias, las publicaciones infantiles pudieron servir para aprender matemáticas, aeronáutica, para leer poemas, cuentos, noticias o para mantener diálogos imaginarios con la familia. Algunos textos aparentemente literarios también señalaban objetivos con una mayor pretensión pedagógica.

El periódico El Mundo de los Niños, cuyo primer número se publicó en Madrid el 10 de enero de 1887, bajo la dirección Manuel Ossorio y Bernard (1839-1904), difundió El foco eléctrico (Aventuras de cuatro niños), una novela por entregas «con la que se pretendía combinar una elemental divulgación de las realidades del mundo de la ciencia con las habituales intenciones instructivas de la época» (García, 1992: 117). Nos hallamos ante una de los primeras relatos científicos para jóvenes, que muestra «una implícita servidumbre a los modelos creados por Verne o a los esquemas de las robinsonadas» (García, 1992: 117), merecedora de unas breves líneas. Debajo del título, consta «Novela científica para la infancia», escrita por José Muñoz Escámez y publicada entre el 30 de noviembre de 1888 y el 20 de abril de 1889, ilustrada por grabados de José Cuevas y de Narciso Méndez Bringa. El protagonista de la obra es el ingeniero Ernesto Rodríguez, inventor, que construye en los talleres Inteligencia y Fuerza, de Valencia, un aparato volador y emprende una aventura con sus hijos; sin embargo, la aventura queda inmersa en un conjunto de descripciones instructivas y detalladas que explican el funcionamiento del aparato:

La habitación en que nos encontramos es extensa, pero apenas podemos movernos, tal es la multitud de objetos que la pueblan: en aquel rincón se ven doce toneles de gran cabida, en los cuales se está produciendo el gas hidrógeno que va a los globos por medio de un tubo de goma; en éste, una dinamo eléctrico Siemens; en los otros hay distintas máquinas, cuyos usos la distancia nos hace desconocer, y en el centro hay una barquilla de forma oblonga muy alargada y de cuyos extremos parten cuatro hélices.

O imparte lecciones de biología, ciencia y tecnología 
-Un arto carpus; -exclamó. -Estamos salvados.

-¿Qué es un arto carpus?-preguntó Enrique con curiosidad.

-Es el famoso y nunca bien ponderado árbol del pan.

$-i$ Conque hemos tropezado con esa providencia de los necesitados, que siempre tuve por fabulosa?

-Pues nada tiene de fabulosa ni de rara, y buena prueba de ello es el ejemplar

-magnífico por cierto- que tenemos a la vista..

-¿Qué propiedades tiene?

-Como ve V., el arto carpus mide de catorce a quince metros de altura, y la circunferencia de su tronco es próximamente de tres metros. Su fruto -que ahora probaremos- es del tamaño de la cabeza de un niño; y de su sabor nada digo, porque acerca de él espero su dictamen. Ocho meses prodiga sus frutos este precioso vegetal, y bastáranos con lo que en seis meses produzca para mantenernos bien los dos por espacio de un año. Además, como si tan excelentes cualidades fueran pocas, sus hojas pueden servirnos a guisa de manteles, y su corteza puede suministrarnos unas fibras muy a propósito para tejidos.

No es de extrañar, pues, que esta educación informal, cuyas líneas fronterizas con relación a la educación formal o no formal resultan en ocasiones difíciles de delimitar, representara su papel en la educación de los infantes de la época.

En el aspecto literario, dejando al margen los aspectos de divulgación científica, las publicaciones infantiles, las secciones y los suplementos dirigidos a los niños que formaban parte de los periódicos generales coadyuvaron a la creación de un corpus consistente de autores y de obras de literatura infantil. Por un lado, estaba integrado por los autores canónicos de la literatura general que tenían una obra no dirigida a los niños, pero que los niños hicieron suya por la selección realizada por los editores -lo que se ha llamado la «literatura ganada», entre ellos Valera, Echegaray, Pérez Galdós-. Por otro lado, los autores que en mayor medida escribieron para niños: Carlos Frontaura, Manuel Ossorio y Bernard, Julia de Asensi, Pilar Pascual de San Juan, Alfonso Pérez Nieva o Teodoro Baró. Unos y otros fueron conformando un corpus de lecturas para niños que ha perdurado hasta nuestros días en la historia de la literatura infantil. Como afirmaba Baquero (1992: 6): «[...] los cuentos, al pasar a las páginas de los periódicos, no siempre se convertían en fugaz materia literaria, ya que la mayor parte de las veces los propios autores se encargan de coleccionar, en libros, sus narraciones dispersas en diarios y revistas»-. La incipiente literatura infantil española se vio reflejada en las revistas para niños, cuyos autores, a su vez, publicaron sus obras en las colecciones de la misma editorial. Las tendencias narrativas de la época (García, 1992: 71) se manifestaron en estos periódicos de finales del XIX: el cuento infantil de origen folclórico, el reflejo literario del mundo infantil, los relatos científicos 
para jóvenes, los cultivadores del «instruir moralizando», el costumbrismo decimonónico en el cuento infantil.

No puede hablarse de revistas literarias para niños en el siglo XIX, pero sí de los contenidos literarios que incorporaban las publicaciones para niños y familias, en las que se encontraban textos de los más destacados autores de la época. Algunos de los contenidos literarios que surgieron en el último tercio del siglo XIX se publicaron como secciones y suplementos en la prensa para adultos, pero fue durante las tres primeras décadas del siglo XX cuando consiguieron una mayor independencia: caso paradigmático es el de Gente Menuda que verá la luz en distintas etapas en $A B C$ y en Blanco y Negro.

En la primera mitad del siglo XIX, Chivelet (2009: 35) cita como primer suplemento infantil El Impúber, «periódico pueril» que se regaló con el diario El Resumen en su edición dominical: «Esto lo convierte en el precursor de una práctica que se tornará habitual en el siglo XX. Aunque está dirigido principalmente a los maestros, sus páginas se abren a la colaboración de los niños, y sus dibujos y poesías eran esperados por chicos y grandes».

A partir de 1895 se publica la primera sección específica para niños en El Nacional, fundado en 1894. Aparecerá semanalmente con el título de Los Niños y el subtítulo «Los domingos de El Nacional». Ocupaba el pie de las páginas tercera y cuarta, sin llegar a alcanzar la mitad de su formato. Podían encontrarse textos clásicos de Lope de Vega o actuales como los de Clarín o la menos conocida, Carolina Valencia. Las cuatro páginas se publicaron también en formato de lujo por setenta y cinco céntimos, impresas en «magnífico papel cartulina y a dos tintas» y se vendieron en la librería de Fernando Fe, ofreciendo la posibilidad al lector de seguir en uno u otro formato la sección del periódico. «La impresión, hecha en impar y par, facilita su autonomía, previo corte y posterior doblado. Con ese fin goza de fecha y de cabecera propia. Su diseño es modernista, con profusión de adornos florales y la presencia de un simbólico angelito, en clara alusión a la inocencia de los lectores» (Chivelet, 2009: 63-65).

En un intento por ampliar el perfil de sus lectores, los diarios que ya tenían consolidado a un lector adulto interesado por la actualidad o por la moda, según las secciones habituales en la prensa generalista, intentaron responder a las inquietudes del lector infantil que formaba parte de la familia a la que se dirigía el diario con la aparición del suplemento. En una supuesta conversación telefónica entre el lector y el periódico quedaban expuestas las inquietudes del nuevo lector:

-Vamos a ver, amigo Nacional. ¿Quiere usted dejarnos más contentos que unas castañuelas? 
-De eso se trata, hijos míos.

-Pues lo primero que ha de hacer es separar nuestra sección de todas las demás; no queremos nada con gente grave y ceremoniosa. Lo segundo es que nuestra sección ha de ser alegre y entretenida, sin citas sabias ni acotaciones en los márgenes; monda y lironda, con aquella derechura y sencillez que mandaba don Quijote al chico de maese Pedro el titiritero. Ha de tener monos, si tiene historietas, aleluyas y cuentos, será miel sobre hojuelas.

Por lo demás, solicitaba pasatiempos, poemas, concursos... (Chivelet, 2009: 65)

Un suplemento destaca a finales del siglo XIX, el suplemento de El Liberal (3 de enero de 1897), del que nos ocuparemos en este trabajo. Su publicación en la prensa no destinada al público infantil tenía el objetivo de ofrecer una panorámica de la creación literaria que podían leer los niños -hubiera sido escrita para ellos o no- a partir de firmas clásicas de la literatura general y, al mismo tiempo, ayudaba a darla a conocer a un público más amplio que el que accedía con regularidad a las publicaciones para niños y familias. La relevancia del suplemento en la historia de la literatura destinada a la infancia y a la juventud y su escaso conocimiento, hacen necesario realizar una detallada descripción del suplemento es porque a pesar de haber sido considerado como «histórico» (Chivelet, 2009: 66) en la literatura infantil española porque «reunía una completa selección de cuentos, poemas y artículos firmados por nombres de prestigio en la literatura y en la cultura de la época» (García, 1992: 182), sin embargo, no ha sido debidamente destacado en la historiografía dedicada a la literatura infantil.

La edición ocasional de El Liberal con motivo de la proximidad de la festividad de Reyes destacó por la especial relevancia de sus firmas y, como había ocurrido en la referencia anterior a El Nacional, por la nueva perspectiva de lectores y de mercado que se abrió a las empresas editoras. Se trataba de captar nuevos lectores, pero, al mismo tiempo, se le ofrecía una visibilidad mayor a la literatura infantil que había quedado relegada hasta entonces a las revistas para niños y familias o a la prensa pedagógica, a pesar de que en ocasiones concretas aparecieran en la prensa general algunas colaboraciones destinadas a los niños. Se trataba, por tanto, de uno de los suplementos que iniciaron la transición hacia los suplementos literarios infantiles que se publicaron a lo largo del siglo Xx.

El ejemplar de El Liberal abría con una ilustración que abarcaba gran parte de la página. En ella se representaba a un niño mendigo ante un puesto de juguetes y de instrumentos musicales; tras el mostrador, una niña compartía con él un juguete. El motivo de la ilustración tenía que ver con el texto de 
Concepción Arenal de la primera página del número 6.302, un artículo teórico sobre la situación de los niños que servía como contextualización.

En el suplemento se alternaban textos publicados por primera vez con textos recuperados del propio periódico o de otras publicaciones. Al tratarse de un suplemento dirigido a un público infantil, pero publicado en un diario de adultos, se hallaban textos para niños y textos teóricos sobre cuestiones que a la sazón estaban de actualidad: la protección de los niños, la situación de los estudios sobre su psicología, cuestiones de pedagogía. Acompañando los estudios científicos en torno al niño, los cuentos y los poemas, no podían faltar en un suplemento para niños algunos textos que trataran de inculcar enseñanzas y de instruir, mediante la utilización de un tono paternalista.

La primera página la ocupaban el artículo mencionado de Concepción Arenal («Los niños»), los cuentos de Galdós («Rompecabezas») y de Valera («El caballero del azor») y el poema de Manuel del Palacio ( Viendo morir a un niño»).

El artículo «Los niños», firmado por Concepción Arenal era una selección de párrafos tomados de los artículos publicados en Gijón el 1 de mayo de 1876 y 8 de junio de 1877. Concepción Arenal trataba algunos de los temas que había recogido en sus trabajos sobre la beneficenciaª la protección de los niños, su indefensión, niños pobres y niños ricos e intentaba lanzar una campaña de entrega de juguetes de los niños ricos a los pobres, tal como reflejaba el dibujo que abría el suplemento y el artículo.

«Rompecabezas» fue el último de los relatos cortos escrito por Galdós fechado el 1 de enero de 1897 en su etapa de madurez. Se trataba de un relato de tema navideño -en la línea marcada por el periódico para las fechas-que presentaba la historia al modo cervantino encontrada en un papirus. De ritmo ágil, en una primera lectura, al tratarse de uno de los doce cuentos «inverosímiles» (Smith, 1992: 13) puede sorprender la inclusión de este cuento en un suplemento infantil -el término infantil no abarca el mismo periodo que en la actualidad-, pero hemos de tener en cuenta que «Rompecabezas» fue publicado por primera vez en este suplemento de El Liberal como contribución al tema de los Reyes y que el lector infantil gustaba de los cuentos capaces de provocar sorpresa. Se trataba de un cuento complejo que admitía una doble lectura: la literal y la alegórica, y resultaba necesario atender a las indicaciones del narrador para poder llegar a entenderlo.

Ayer, como quien dice, el año Tal de la Era Cristiana, correspondiente al Cuál, o si se quiere, al tres mil y pico de la cronología egipcia, sucedió lo que voy a

2. Artículos sobre beneficencia y prisiones, vol. III y vol. IV.

Anales, 26, 2014, pp. 257-274 
referir, historia familiar que nos transmite un papirus redactado en lindísimos monigotes. Es la tal historia o sucedido de notoria insignificancia, si el lector no sabe pasar de las exterioridades del texto gráfico; pero restregándose en éste los ojos por espacio de un par de siglos, no es difícil descubrir el meollo que contiene.

La lectura de este texto por los niños probablemente quedaría en la lectura literal que corresponde a un lector ingenuo que comienza con una lectura superficial (Mendoza, 2000: 122). -al modo de lo que sucedía con la farsa infantil de Valle-Inclán, La cabeza del dragón que, escrita para niños con algunos elementos propios de los cuentos maravillosos, tenía implicaciones políticas y literarias difíciles de entender por los destinatarios debido a su competencia literaria-; lectura literal que no iría más allá de los elementos que pudieran atraer la atención del joven lector: la utilización de fórmulas de presentación de los cuentos - «Pues señor... digo que aquel día o aquella tarde»-, el lugar exótico, la peripecia de la huida, el encuentro con un desconocido que regalaba una moneda al niño, la referencia bíblica a la Sagrada Familia -que recordaba, por ejemplo, al Pelusa del Padre Coloma pero sin su enfoque moralizador-y, sobre todo, los juguetes y su asombrosa transformación. Sin embargo, el adulto, conocedor de la realidad de la época, al realizar una lectura alegórica que correspondería a un lector competente, reconocería los aspectos que señala Smith (1992:199) citando el trabajo de J. Hoar: identificación de Alfonso XIII «el niño picotero», de Sagasta como uno de los caudillos con cabeza de pastor, de la Iglesia entrometida representada por los curas cabezudos, del próximo desastre del 98 en los guerreros sin cabeza... «es una advertencia velada del Rey de Reyes (un regalo de Reyes) al rey de España sobre reinados problemáticos, con Galdós en el papel de facilitador evangélico».

Los tres rasgos destacables de los cuentos galdosianos: lo fantástico, lo alegórico y lo infantil (Gutiérrez, 2001: 18) se dan en «Rompecabezas», aunque más próximo a lo alegórico que a lo fantástico. En el caso de lo infantil, el cuento reflejaba el interés de Galdós por el mundo del niño «a la vez que traslada una concepción del cuento que parece indisolublemente ligada a este ámbito» (Gutiérrez, 2001: 19). El propio Galdós preparó una edición de sus Episodios Nacionales para niños.

Lo cierto es que un texto de esta complejidad plantearía numerosas dificultades a un lector novel que se quedaría solamente en la lectura literal, pero quedaría cautivado por la narración. «Nos hallamos ante un verdadero cuento, que camina hacia su desenlace con paso firme, en el que no hay digresiones ni demoras de ningún tipo. Rompecabezas se convierte así no solo en 
broche de oro que cierra la obra cuentística de Galdós, sino en perfecto reflejo de la historia del género a lo largo del siglo [...]» (Gutiérrez, 2001: 18)

El poema «Viendo morir a un niño» de Manuel del Palacio había sido publicado en La Ilustración Española y Americana el 15 de octubre de 1874 y recogido en el libro Letra menuda, de 1877, aunque en el periódico está datada el 31 de diciembre de 1896.. «Es una obra miscelánea que comprende once breves textos en prosa y un centenar de textos poéticos». (Voces, 2002: 222). Pertenecía a los poemas clasificados por el autor como elegíacos. Se trataba de un poema sencillo, formado por dos seguidillas compuestas, en el que el poeta reflejaba la muerte como huida del mundo.

Vas a morir, y lloras,

iprenda querida!

¡Cómo se ve que ignoras

lo que es la vida!

Si lo supieras,

del placer de dejarla

te sonrieras.

Avecilla enjaulada, torna a tu nido, de la prisión dorada te has redimido.

¡Triste del ave cuando cantar no puede ni volar sabe!

El cuento de Juan Valera «El caballero del azor» fue publicado por primera vez en el número de El Liberal. Lo escribió a la vuelta de Viena. Junto con «El pájaro verde», «El espejo de Matsuyama» $\mathrm{y}$ «El pescadorcito Urashima» en la actualidad son los cuentos más conocidos por el público infantil. Su cercanía al joven lector se produce por «búsqueda de la identidad por parte del protagonista, implicación del lector en esa búsqueda, utilización de fórmulas de la literatura popular, respeto a la edad de los lectores, presentación adecuada de los misterios de la vida, apuntes éticos sobre normas de vida» (Sánchez, 2003). Lo cierto es que, al margen de la presencia de la figura de Bernardo del Carpio en la historia literaria española, también formó parte del catálogo de la editorial barcelonesa Araluce, destinada a un público juvenil, a quien en su labor de promoción de la lectura intentaba dar a conocer obras y autores clásicos de la literatura española y universal, cuentos y leyendas y biografías en versiones adaptadas. En 1937 fue incorporado a su catálogo Bernardo del Carpio. Epopeya que evoca las hazañas heroicas de este paladín español relatada a los niños por José Baeza con ilustraciones de José Segrelles. 
Entre los textos literarios de la página dos se publicaron también breves retratos de maestros, de Lucas Zapatero y Moreno, y de Margarita Ferrer, ambos maestros decanos de las Escuelas Municipales de Madrid. En ellos, el propio maestro hablaba del ejercicio de su profesión o el diario hacía un elogio de su figura.

El pedagogo Manuel Bartolomé Cossío publicó por primera vez «El estudio del niño» en El Liberal y coincidió con el año de publicación de su libro La enseñanza primaria en España. Renovador pedagógico, seguidor de Francisco Giner de los Ríos y responsable de los planes de estudio en la Institución Libre de Enseñanza, planteaba en su artículo las dos direcciones vigentes en el estudio de la infancia: «el problema antropológico y el problema étnico: el niño en el individuo y el niño en la conciencia y en la sabiduría populares». Como pedagogo, Cossío era consciente de la importancia que tenía en la renovación educativa la figura del niño y fijaba el punto de partida: al conocer al niño, conoceremos cuáles son los rasgos que lo han convertido en un artista, en un científico o en un escritor «el niño es el padre del hombre».

Hay que pedir al niño que nos deje ver en su alma clara y sencilla cómo se ha llegado a las complejas construcciones del grandioso pensamiento de un Platón o de un Hegel; hay que reunir amorosamente, comparar, interpretar los rasguños vacilantes, los toscos monigotes que traza el niño en sus primeros años, para ponerse en camino de saber, si algún día so sabe, el misterioso proceso que lleva a concebir y a pintar Las Lanzas o el techo de la Capilla Sixtina; hay que notar el primer llanto del recién nacido, sus primeros gritos, sus primeras balbucientes palabras, su primer juego, el primer indicio de su libre representación ideal, si queremos llegar tal vez a la ignorada fuente de donde sacaron los raudales de su rítmica belleza literaria Cervantes y Shakespeare, y así de la moral, de la religión, de la industria, de todo; porque la poética intuición de que «el niño es el padre del hombre», ha sido ya consagrada por la ciencia, que añade además «hermano de la raza».

En el melodramático «El hogar frío», Constantino Gil, cultivador de diversos géneros, aunque mordaz escritor teatral y de prosa humorística, trató el tema de la noche de Reyes y de la ausencia del padre que se encuentra en la guerra, aderezado todo con una referencia al periódico en el que lo publicaba y las oportunas enseñanzas:

¿Pero, estás llorando?

$$
\text { -Sí. }
$$

-No llores, que lo humedeces.

- ¿Y qué importa? Así estará

con mis lagrimitas lleno,

y acaso algún Rey dirá:

«Esto es de un niño muy bueno, 
que llora por su papá»,

-Ea; ya está hecho el cajón;

y aunque sea de papel,

como verán tu intención,

los Reyes pondrán en él

lo que les dé la Nación.

Eusebio Blasco, colaborador de El Liberal, publicó el cuento «Manolín», según explicaba el propio periódico porque el autor no pudo enviar el artículo prometido y se eligió «uno de sus más hermosos cuentos» publicado en 1880 «que no ha sido reproducido desde entonces». Fue recogido en el libro Malas costumbres, y publicado también en el Día de Moda que Blasco dirigía el 12 de julio de 1880. Era un cuento de tema social en el que se denunciaba la explotación de los niños, Manolín el niño criado de ocho años que servía en casa de la condesa, y se defendía uno de los temas de la época: la protección de la infancia. El texto de Blasco planteaba la hipocresía social ante el tema.

Ayer en la mesa, un senador nos hablaba muy satisfecho da que se había votado la ley de niños.

-¡En adelante -decía- los niños hallarán protección; no se les explotará, no serán víctimas de nadie! ¡Manolín, échame agua!

Todo el mundo celebró la novedad; pero nadie reparó en Manolín, que servía, y a quien yo estuve por decir:

-¡Niño Manuel, en nombre de la ley, siéntate a comer con nosotros!

En la página tres, el pediatra y creador del Consejo Supremo de Protección de la Infancia, Manuel de Tolosa Latour, escribía «El Rey de la casa», la historia de un paciente niño como ejemplo de superación. El tema de los Reyes -el niño es agraciado con el rey del roscón- era un pretexto para el verdadero mensaje de la historia: la necesidad de que la familia y el Estado se responsabilizaran de la «crianza física, intelectual y moral de todo niño rico, pobre, huérfano o desamparado».

El cuento «Las ternuras de la muerte» de José Echegaray se recogió en el volumen con Los tres sueños de Colilla. Los anteojos de color. Las piedades del sultán. Las dos orillas del río (1901). El cuento, de gran intensidad dramática y con una teatral puesta en escena, ofrecía la afectuosa y compasiva visión del personaje de la Muerte que contemplaba el dolor de una niña que había visto fallecer a su madre. Echegaray parecía dirigirse a un lector niño al utilizar un tono íntimo, conmovedor, para atenuar la frialdad y la crueldad de la Muerte, a quien humanizaba y describía con sutil ironía. La Muerte, mostrando sus «ternuras», empatizaba con el dolor de la niña.

Y así estuvieron: la muerta en medio; a un lado la niña arrodillada, llorando,

llamando a su madre y con los puñitos en los ojos; al otro lado la Muerte, 
arrodillada también, bajándose casi al nivel de la niña y sosteniendo abiertos los brazos de la madre. Así estuvo esperando con paciencia suma; porque nadie tiene más paciencia que la Muerte.

Al fin la niña miró; vio aquellos brazos que se abrían, y se dejó caer en ellos contra el pecho de su madre. La Muerte, con mucho cuidado, cerró los brazos y puso las manos de la madre muerta sobre la cabecita de la niña.

Sobre el contexto familiar había dos colaboraciones: la primera, de Enrique Pérez Escrich quien escribió sobre «El abuelo y el padre» con una de sus especialidades, los diálogos, que en esta ocasión, se centraban en un diálogo entre un abuelo y un padre para revindicar el papel que debía desempeñar el abuelo en la familia frente al del padre. La segunda colaboración acerca del contexto familiar fue de «Kasabal» pseudónimo de José Gutiérrez Abascal que transmitía una edulcorada visión del niño en el artículo «Los niños»: «Los níños son indudablemente lo más hermoso de la creación», «La vida sería muy árida y muy triste sin la niñez. Un hogar sin ellos es como una colmena sin abejas, como un jardín sin flores».

En la página cuatro, de Emilia Pardo Bazán se incorporó el cuento «La paz» que, partiendo de un ambiente escolar, trataba de peleas entre bandos de niños, había sido recopilado en En tranvía (Cuentos dramáticos) (1901). Cabría plantearse el motivo de la selección de este cuento, que destaca por su simbolismo, para un suplemento para niños. ¿Por el ambiente escolar en el que se desarrollan los juegos de guerras coloniales entre bandos de niños, el de Pepito Lancín y el de Riquito (Federico) Polastres, entre los españoles y los mambises? ¿Por el desenlace?

-Y entonces, ¿cómo va a ser, bruto animal? Si no éramos contrarios, cata que no había guerra.

-iPues que la haya que no la haya!

Eres muy listo tú. Déjanos a nosotros ser españoles, y ser vosotros los mambises.

-No puedo -objetó con suprema dignidad Lancín.

$-¿$ No? ¡Verás si puedes, rayo! Del lapo que te voy a soltar... te dejo negro y estarás muy propio.

[...]

Al escucharlo por segunda vez, al ver ondear la bandera, la hueste de Riquito se precipitó y rodeó a Lancín, aclamando lo mismo que él aclamaba con voces atipladas y roncas; pero con una cordialidad y alegría que revelaba disposiciones pacíficas, y el jefe, contuso, no encontrando solución al problema más fácil les parecía arremeter contra todos, contra el enemigo y contra los que se le pasaban traidoramente -exclamó avergonzado, llorando como un becerro: -Me has partido... Esto no sirve... 
No puede haber batalla... Si todos éramos españoles, no nos podíamos pegar... También te aseguro que cuando yo te pille y no esté delante nadie y no tengas bandera...

- ¡Vaya una gracia que harás! Tienes una fuerza que pareces un buey -contestó altivamente Lancín disparando su revólver al aire, mientras los dos ejércitos fraternizaban. Y Riquito se arrepentía ya de su amenaza poco generosa.

Las mamás de los combatientes nunca supieron de la que habían escapado.

Sinesio Delgado, siempre mostró su interés por la literatura para niños, por tanto, una parte considerable de sus obras de teatro, de poesía y de la publicada en la prensa la dedicó a la niñez. Colaboró con «En vela», un poema de amor y desengaño en el que Delgado utilizó la redondilla para ir desarrollando la historia en la que el beso de un niño resultaba ser terapéutico: «-¡Ea! No me da la gana, / ¿sabes? ¡No paso por eso! / ¡Como me robes su beso, / te tiro por la ventana!

En el apartado de artículos, de nuevo una perspectiva no literaria, la del Dr. A Pulido «Ternuras»- Historias de la medicina vividas por Pulido con niños en la que narraba un episodio con Castelar y mostraba su interés por los estudios sobre la psicología del niño.

Jacinto Octavio Picón con el cuento «Cosas de ángeles» describía a los ángeles y sus funciones. Servían de ayudantes de los Reyes Magos. Sin embargo, sorprendía el final.

$-¿$ Oyes? ¿Qué ruido es ese?

El ángel contestó:

-Me lo figuro. Es que lloran y patean

los chicos que se han quedado sin juguetes.

San Pedro repuso:

-Pero con todo lo que llevasteis, ¿ ha habido descontentos? ¡Mal habéis hecho el reparto! A unos habréis dado mucho y a otros nada.

-¡Claro está!-exclamó el ángel.

-iPues no lo entiendo.

Entonces el ángel dio esta explicación:

-Nosotros hemos puesto los juguetes, según su clase y valor, en los balcones y ventanas de los palacios y casas donde hemos visto colocados zapatitos, botitas, y hasta alpargatas: pero donde no había nada, pasábamos de largo. Si Dios no dio a los padres de esos niños ni aun para comprarles zapatos, ¿cómo habíamos de atrevernos a dejar el regalo?

En la línea del diálogo mencionado más arriba entre el abuelo y el padre (de Pérez Escrich), en la página 5 Vital Aza -dramaturgo, humorista, poeta- escribió «Los nietos» con el tono jocoso que caracterizó su obra. Trataba de las travesuras de los nietos y de la felicidad que sentía al estar con ellos: "¡Que 
para morir en calma, /cuando me llame a su lado / me encuentre yo rodeado / de mis nietos de mi alma».

«Fernanflor», pseudónimo de Isidoro Fernández Flores narraba en el cuento «La oruga» el episodio en el que la niña-La Calandria- quedaba huérfana -uno de los motivos de la literatura de la época-. Sería el maestro de escuela de Carrizosa, quien la había visto intentando alcanzar una oruga, el que la cobijaría. Al despertar, junto a ella encontraría una mariposa. Mediante la metáfora de la oruga, el autor planteaba el despertar a una nueva vida de la niña y reflejaba el paso del tiempo.

Felipe Pérez y González colaboró con unos monólogos infantiles alrededor de la «Víspera de Reyes», en los que alternaba la tristeza de una noche de Reyes en la que fallecía un hermano con el humor de los otros dos monólogos.

En la página seis, Rafael Salillas publicó «Candelitas. Historia de un niño delincuente». Salillas trasladó al texto sus estudios sobre la influencia que el medio tenía en la delincuencia -niño Candelitas- teniendo en cuenta que el delincuente era sujeto y objeto de su investigación -su lenguaje, su psicología y su contexto.

Manuel Reina se sumó con un fragmento del Canto I, cuarta parte, «Rayo de sol (fragmento de un poema inédito)» recogido en el libro publicado en 1897 con el título Rayo de sol: poemas y otras composiciones.

Cerró la parte dedicada a los niños, el artículo «La enseñanza materna», de José Zahonero, colaborador de más de una treintena de cabeceras, entre ellas, en publicaciones para niños a quienes dedicó algunos de sus cuentos. En su artículo defendía, partiendo de Froebel y de las lecciones de cosas de Sheddon, el uso del cancionero popular infantil al que denominaba «cancionero popular educativo» para el aprendizaje gradual del niño y para su conocimiento del mundo.

Dulcísima vida de libertad, de amor y de paz; germen de progreso, cancioncillas de una pueblo que había comprendido el valor libre, gozoso, de la enseñanza, revelado, entre otros modos, por el profundo sentido de la obra de Lope de Vega, La dama loba... La enseñanza no resulta si no nos llega al corazón.

La gran cantidad de publicaciones periódicas dirigidas a un lector adulto durante el siglo XIX -que había comenzado a incorporar a finales del siglo secciones y suplementos infantiles-, se correspondió con la considerable nómina de prensa y revistas para niños. Estas circunstancias reflejaban la importancia que la literatura para niños iba tomando en una época que, además de ver al niño como lector en formación, lo vislumbraba como potencial consumidor.

El suplemento del número 6.302 de El Liberal significó un tramo más en la literatura para niños (García, 1992; Chivelet, 2009) por la importancia 
de las firmas, de sus textos -inéditos en algunos casos-, por la variedad de géneros $\mathrm{y}$, sobre todo, por el reconocimiento de un receptor específico que se debía tener en cuenta al seleccionar los textos. El suplemento se planteó para un doble destinatario: el lector adulto y el lector infantil. El lector adulto podría estar informado de las líneas de investigación que se desarrollaban sobre el niño desde el punto de vista psicológico, pedagógico y se convertía en mediador; el lector infantil accedía a cuentos y poemas elegidos para él, que podían ser leídos también con los adultos y por los adultos. La literatura infantil española seguía su andadura.

\section{Bibliografía citada}

ARAnGO, M. ${ }^{a}$ Purificación, «La prensa infantil del siglo XIX. Origen de los tebeos actuales» Educación y biblioteca, 1 (1989), p.14.

Baquero Goyanes, Mariano, El cuento español. Del Romanticismo al Realismo, Madrid, CSIC, 1992.

Bravo Villasante, Carmen, Historia de la literatura infantil española, Madrid, Escuela Española, 1985.

Castro Alonso, Carlos A., Didáctica de la literatura, Madrid, Anaya, 1969.

CHECA Godoy, Antonio, Historia de la prensa pedagógica en España, Sevilla, Universidad. Servicio de Publicaciones, 2002.

CHIVELET, Mercedes, La prensa infantil en España. Desde el siglo XVIII hasta nuestros días, Madrid, SM, 2009.

FRANCO, Marie, «Para que lean los niños: Segunda República y promoción de la literatura infantil», en Desvois, J.M. (coord.), Prensa, impresos, lectura en el mundo hispánico contemporáneo. Homenaje a Jean F. Botrel, Burdeos, Universidad, 2005, pp. 251-272.

GARCÍA PADRINO, Jaime, Libros y literatura para niños en la España contemporánea, Madrid, Fundación Germán Sánchez Ruipérez, 1992.

GARCÍA PADRINO, Jaime, Formas y colores: la ilustración infantil en España, Cuenca, Universidad de Castilla-La Mancha, 2004.

GutiÉRREZ DíAZ-Bernardo, Esteban: «Introducción a Benito Pérez Galdós», 13 cuentos, Madrid, Edaf, 2001.

Llorens García, Ramón F., «Magda Donato (Carmen Eva Nelken)», en Cerrillo, P.C.\& Miaja, T. (coords.), La literatura infantil y juvenil española en el exilio mexicano, San Luis Potosí, El Colegio de San Luis-UCLM, 2013, pp. 134-150.

Mendoza Fillola, Antonio, «El lector ingenuo y el lector competente: pautas para la reflexión sobre la competencia lectora», Puertas a la lectura, núms. 9-10 (1996), Badajoz, Universidad de Extremadura, pp. 120-127.

Petrini, Enzo, Estudio crítico de la literatura juvenil, Madrid, Rialp, 1981. 
SÁNCHEZ GARCÍA, Remedios, «El caballero del azor, de Juan Valera, modelo válido de literatura juvenil decimonónica», Elvira: Revista de Estudios Filológicos, núm. 7 (2003), Granada, Universidad de Granada, pp. 29-37. <URL: http:// www.cervantesvirtual.com/nd/ark:/59851/bmcwh310>; [consulta: 12 junio 2014].

Smith, Alan E., Los cuentos inverosímiles de Galdós en el contexto de su obra, Barcelona, Anthropos, 1992.

Voces ERgueta, Francisco J. La obra en verso y en prosa de Manuel del Palacio. Tesis doctoral. Universidad de Valladolid, octubre de 2002; <URL: http://www. cervantesvirtual.com/nd/ark:/59851/bmc4fln7> [consulta: 12 junio 2014].

Fecha de recepción: 30/09/2014

Fecha de aceptación: 19/10/2014 